\title{
Reformation and Exploration in Physics Experiment Teaching
}

\author{
Maoyong Tang $^{\mathrm{a}}$ and Yaxiang Bai ${ }^{\mathrm{b} *}$ \\ School of Science, Dalian Ocean University, Dalian, Liaoning Province, China \\ atangmaoyong@dlou.edu.cn, b1450917123@qq.com
}

\begin{abstract}
Keywords: Physics experiment; Teaching method; Teaching content; Ability of creation; Experiment teaching reformation
\end{abstract}

\begin{abstract}
In order to improve the quality of physics experiment and cultivate the innovative person with ability of independent scientific research, traditional physics experiment teaching method and content must be reformed, In this paper, the reformation and exploratory researches of physics experiment teaching, especially in teaching method and content are introduced, Through the reform and practice, the teaching and learning quality have been greatly promoted. The learning enthusiasm has been inspired. The overall capability of students in practice and innovation has been markedly improved.
\end{abstract}

\section{Introduction}

In science and engineering teaching of modern college, experiment of college physics is one of the most main courses to enhance the students' practical ability and improve the students' independent innovation ability [1-2].

The physics experiment teaching is an important part of college students' practice teaching and it plays an irreplaceable role in the cultivation of high-quality innovative talents [3-4]. With the rapid development of science and technology and the continuous progress of society, the training contents and training mode of the original physics experiment of the applied physics major in our school has been unable to meet the demand for talents in the modern society. The physics experiment teaching must keep pace with the times and carry out in-depth reform and practice with the thought and philosophy of modern educational teaching, so as to adapt to the increasingly high requirements of the society for talent knowledge structure and scientific quality. Therefore, with the cultivation of the college students' innovation application ability as the goal, we updated and optimized the teaching contents of the current applied physics experiment.

\section{The reformation and exploratory researches of physics experiment in teaching content}

In the experimental project configuration, on one hand, we eliminated some validated experiment projects with single contents, increased the application of Holzer element, the measurement of magnetoresistive sensor and magnetic field, design and application of sunglasses, measurement and analysis of fuel cell characteristics, study of solar cells and photovoltaic characteristics research and other comprehensive experimental projects, enriched the amount of information and knowledge of the opened experimental projects, compiled and published the experimental materials Physics Experiment for the applied physics major in our school. On the other hand, we also studied and developed the seawater refractive index measurement, electronic thermometer design and body temperature measurement, pressure sensor design, heart rhythm and blood pressure measurement, body reaction time test, auditory threshold measurement and other experiment subjects that mix physics and ocean, physics and biology, physical and environment [6], edited and published the "Design and Application of Innovative Physics Experiment" materials and strengthened the innovation of applied experiment projects, so that the experimental teaching contents can be closely related to scientific research, engineering and social application. Thus, it could effectively improve the students' scientific thinking and innovative ability. 


\section{The reformation and exploratory researches of physics experiment in teaching method}

In teaching methods, the previous physics experiment teaching basically follows the traditional teaching mode. In other words, teachers first let students preview, introduce experimental purpose, experimental principle, experimental methods and experimental steps to students, and finally make students finish experiments according to the teachers' instruction. In the course of time, students develop the passive reception and passive experiment habit. Many students never thought many problems, including what is the function of the experiment; why to do the experiment; why use the experimental method; what are advantages and disadvantages of the method; are there better experimental methods. This greatly affects the cultivation of students' independent thinking and innovation ability and reduces students' experiment interests and enthusiasm. Therefore, we tried to improve the experimental teaching method, changed the traditional and single teaching mode, introduced the introduction type, conception type, discussion type and other teaching methods into experimental teaching, and adopted "introduction type" teaching way, so that students can be clear about the experiment principles and guiding ideology of experimental design. The purpose is to carry out the systematic training of the basic experimental skills and basic measurement methods. For some instruments, for example, the polarimeter is "black box" instrument, the components are sealed in the interior. It is difficult for students to know the function of all components and experimental principles. Some teachers combine the corresponding polarizer, analyzer and half wave plate, explain principles and observe the phenomenon. They also refit the photocell and micro ampere meter, so the observation of light intensity changes is switched into the observation of current changes. Then the component and phenomenon involved by the whole polarimeter are displayed in the classroom. Through the actual observation of the real situation, the class can make full use of the students' visual and auditory function with the combination of teachers' verbal explanation, thus arising students' thinking. The classroom atmosphere is very active. Finally, students' feeling will be that the contents are authentic and the principles can be understood and grasped easily; later a student switched to use microcurrent multiplication table from a microammeter in order to make the measurement more accurate. Then teachers can not only save time, but also greatly improve the teaching effect.

The comprehensive experimental teaching with the use of "discussion type" teaching method can cultivate students' comprehensive experiment ability and experimental design innovation ability, strengthen the knowledge depth and breadth, and connect to the reality. Teachers can break the low grade students' obedience to books and authority to a certain extent, inspire students to actively think, encourage exploration and strengthen the training of creative ability. Teachers teach the different treatments of the related theories and technologies of the experiment, debate and comparison, the feature of related materials and the places need to be improved; they also discuss our experimental arrangement or the problems or contradictions of equipment. The problem revelation has special enlightenment role in students' learning. The problems discovery and the deficiencies explanation will not reduce students' learning enthusiasm, but strengthen the motivation in exploring and studying problems. The comprehensiveness and multi-level can make students have access to more contents within the limited class hours, learn more experimental knowledge and skills, and gradually develop the habit of the system thinking from traditional thinking mode while analyzing and studying problems. The multi-level also provides flexible teaching conditions for the students with different gumption, different basis and different starting points.

The experimental teaching with the use of "conception type" teaching method can cultivate students' ability to analyze and solve problems, and mobilize students' enthusiasm and experimental interests [7]. For example, when teaching "the measurement of resistance using the bridge method," the teacher will first allow the students to measure the value of an unknown resistance, and then analyze the advantages and disadvantages of the typical "voltammetry resistance measurement" that they have designed. The teacher will then raise questions for the students to contemplate and answer according to their design plan. At the end of the session, the teacher will introduce "the measurement of resistance uses the bridge method" to the students and allow them to compare it with the other designed methods.

In another example, when measuring the specific heat capacity of solids, the teacher will initially 
allow the students to design a measurement technique for the heat capacity of an unknown metal. Once the students have developed various methods, the teacher will organize the students and ask them to discuss and analyze the rationality, feasibility, accuracy, advantages, and disadvantages of these methods. Then, the teacher will introduce the method that will be adopted in class and ask the students to compare it with the methods that they have designed. In this manner, the students will be able to analyze the advantages and disadvantages of the established method, and consequently, propose better methods. Through this practice, the ability of the students to analyze and solve problems will be trained and their initiative and enthusiasm will be developed. Even if the students fail to design a reasonable experimental plan, this approach will have far-reaching significance in developing the comprehensive experimental design ability of the students.

For another instance, in the late stage of the experimental course, we selected several experimental topics for students, provided some necessary instruments and let students design the experimental schemes, so as to train students' comprehensive experimental ability and problem-solving ability; we wrote experimental contents, experimental principle and experimental procedures, measured the corresponding experimental data and results according to experimental scheme, and then wrote experimental reports or papers. Finally, teachers evaluated their experimental reports or papers, organized students to discuss the feasibility, advantages and disadvantages of various experimental methods, the accuracy and reliability of results, and put forward improvement suggestions. We adopted multimedia and blackboard writing, teaching video and other teaching methods to improve the teaching effect. In addition, we also used CCD system and assembled experimental instruments in some experimental classes to explain experimental principles. By this way, teachers can teach clearly and students can understand. And it also avoids the students' forward congestion situation while teachers giving lectures; meanwhile, it greatly improves students' understanding of experimental principles and experimental design ideas and receives good teaching effects.

\section{Acknowledgements}

This research was financially supported by the Dalian Ocean University.

\section{References}

[1] J.S.Huang: Physical Experiment of College,Vol. 18 ( 2005) N0.1, 75-77. (In Chinese)

[2] L. X. Wang: Experiment Science\& Techno logy, 7 (2009) N0.4, 69-71. (In Chinese)

[3] C.J. Ding, J. Lu and J.F. Wang: 2010 International Conference on E-Health Networking, Digital

[4] Ecosystems and Technologies (Shen Zhen, China, April 17, 2010) Vol. 1, p.36.

[5] L.F. Li, Y.X. Zhang: Experimental Technology and Management, 22 (2005) 11-14. (In Chinese)

[6] N.C. Liu, J. Q. Li: Journal of Henan Education Institute（Natural Science Edition,21 (2012) 58-60.(In Chinese)

[7] J.Wang, J.W. Chi: Design and Application of Innovative Physics Experiment (Chinese Science Press, China 2015)

[8] Y.X. Bai, G.J. Yang and Y.C. Hu, Increasing the Creative Thinking Ability of Students via the Conceptual Teaching Method. 2016 2nd International Conference on Modern Education and Social Science (Wuhan, China, April 15-17, 2016) p.587-589. 